\title{
The challenge of recurrent hepatitis $C$ virus in liver transplant recipients
}

\author{
Paul J Marotta MD
}

PJ Marotta. The challenge of recurrent hepatitis $\mathrm{C}$ virus in liver transplant recipients. Can J Gastroenterol 2004;18(Suppl C):19C-26C.

Hepatitis C virus (HCV) has become the leading indication for liver transplantation (LT) worldwide. Short-term graft and patient survival after LT in these individuals is comparable with other indications for LT. There is, however, a disturbing trend for decreased survival over the longer term. The natural history of HCV infection after LT is evolving. Its early recurrence and the wide spectrum of recurrent disease is recognized, from minimal histological and clinical disease to very aggressive forms of hepatic damage such as fibrosing cholestatic hepatitis. There is growing concern that recurrent $\mathrm{HCV}$ is becoming more aggressive. Although many factors have been implicated, the causes have not been fully elucidated. Interferon-based antiviral therapy is challenging to use in this patient population because of significant toxicity. Nevertheless, these agents have some efficacy, and pegylated interferons, which are now being used more frequently, achieve superior response rates. The role of liver retransplantation in this patient population is controversial, because of both a reduced survival rate and an overall shortage of organ donors. The present review discusses the challenges that occur in LT recipients with HCV.

Key Words: Cirrhosis; Hepatitis C; Liver; Transplantation

\section{Le défi du virus récurrent de l'hépatite $\mathrm{C}$ chez les transplantés du foie}

Le virus de l'hépatite $\mathrm{C}(\mathrm{VHC})$ est devenu la principale indication de transplantation du foie $(\mathrm{TF})$ de par le monde. Une transplantation à court terme et la survie après la TF chez ces individus sont comparables aux autres indications de TF. Il existe toutefois une tendance perturbante de diminution de la survie à long terme. L'évolution naturelle de l'infection au VHC après la TF évolue. Sa récurrence précoce et le vaste spectre de maladies récurrentes sont reconnus, variant entre une maladie histologique et clinique minimale et des formes très agressives de lésions hépatiques telles que l'hépatite cholestatique fibrosante. Il existe une inquiétude croissante que le $\mathrm{VHC}$ récurrent devienne plus agressif. Bien que de nombreux facteurs aient été mis de l'avant, les causes n'ont pas encore été complètement élucidées. Un traitement aux antiviraux à base d'interféron est difficile à utiliser au sein de cette population de patients, en raison d'une importante toxicité. Néanmoins, ce type de traitement a une certaine efficacité, et les interférons peguylés, qui sont maintenant utilisés plus souvent, obtiennent des taux de réponse plus élevés. Le rôle de reprises de TF est controversé au sein de cette population de patients, en raison tant d'un taux de survie réduit que d'une pénurie globale de donneurs d'organes. La présente analyse porte sur les défis qui surgissent chez les transplantés du foie atteint du VHC.
$\mathrm{H}$ epatitis $\mathrm{C}$ virus (HCV)-related liver disease is a serious global concern that is challenging health resources worldwide and posing difficult ethical questions to the transplantation community. Currently, the only definitive therapy for patients with end-stage HCV-related cirrhosis is liver transplantation (LT) $(1,2)$. Unfortunately, patients who undergo lifesaving orthotopic LT face a cruel irony: the new liver does not eliminate HCV infection. HCV almost universally reinfects the transplanted liver; more than $90 \%$ of transplant recipients continue to have detectable serum HCV RNA $(2,3)$, and may develop HCV-related liver disease again, possibly leading to graft failure, liver retransplantation or death $(1,2,4)$.

The present review addresses the medical, economic and ethical challenges associated with recurrent HCV infection in LT recipients and some of the controversies in this area.

\section{NATURAL HISTORY OF POST-TRANSPLANT HCV INFECTION}

\section{Epidemiology of primary $\mathrm{HCV}$ infection}

In most regions of the world, $\mathrm{HCV}$ is the most frequent cause of progressive liver disease $(1,2,5)$. After primary infection with $\mathrm{HCV}$, the majority of patients ( $70 \%$ to $85 \%$ ) eventually develop chronic hepatitis and, within 20 to 30 years, $15 \%$ to $20 \%$ progress to cirrhosis or end-stage liver disease (ESLD) $(4,6)$. In developed regions of the world, such as North America, Europe and Australia, ESLD due to HCV infection is now the most common indication for LT (6).

Essentially a global viral pandemic, HCV infects as many as 170 million people worldwide. The prevalence of exposure in those living in developed countries, as assessed by the presence of serum anti-HCV antibodies, is $1.5 \%$ to $2.0 \%$, including $1.8 \%$ in the United States (US). The highest prevalence is in Egypt, where almost $25 \%$ of the population is infected (7). HCV infection rates vary geographically, with almost four million people in the US (of whom 2.7 million have active disease) $(4,6)$ and over five million people in Europe being infected $(6,8)$.

In the US, the Centers for Disease Control and Prevention estimated that 8000 to 10,000 deaths each year are related to HCV. The Centers for Disease Control and Prevention also expects $\mathrm{HCV}$-related mortality rates to triple over the next 20 years and, if this prediction is borne out, HCV could cause greater mortality than AIDS. Some of this excess mortality could be reduced by LT, but the widespread use of this lifesaving procedure would overburden the health care system.

\footnotetext{
Multi-Organ Transplant Program, London Health Sciences Centre, London, Ontario

Correspondence: Dr Paul J Marotta, Multi-Organ Transplant Program, London Health Sciences Centre, University Campus,

339 Windermere Road, London, Ontario N6A 5A5. Telephone 519-663-3406, fax 519-663-3858, e-mail Paul.Marotta@lhsc.on.ca
} 


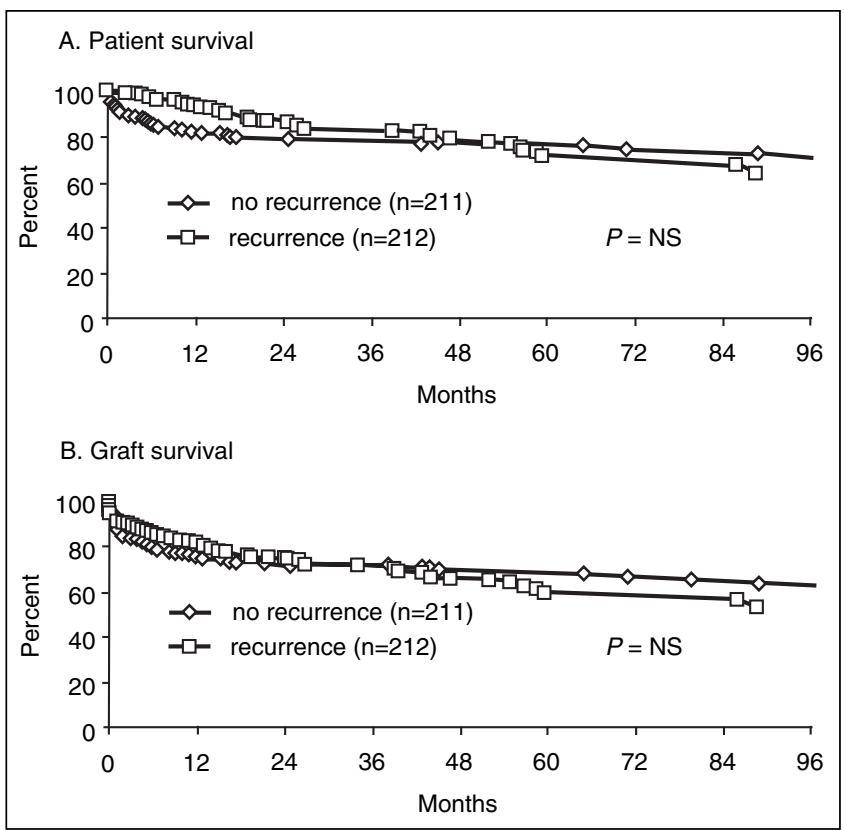

Figure 1) Patient and allograft survival in liver transplantation recipients after histological recurrence of hepatitis C virus infection. NS Not significant. Reprinted from reference 17 with permission

\section{Economic impact and social burden}

Significant health care costs and a heavy social burden are the direct result of the magnitude of this comparatively unpublicized disease. Relatively few estimates of the economic consequences of $\mathrm{HCV}$ are available, and those that are available are limited to industrialized nations. In the US in 1997, the consequences of HCV were estimated to cost US $\$ 5.46$ billion. Although the indirect costs of $\mathrm{HCV}$-related disease (including pain and suffering, as well as undocumented and unpaid care from family members) are significant, they are generally underestimated or, more often, completely omitted from economic analyses (9).

Individuals with HCV suffer a reduction in health-related quality of life, as do LT recipients with recurrent HCV. Functional performance, physical functioning and health-related quality of life are all impaired in HCV-positive LT recipients compared with recipients without recurrent HCV or patients who had undergone LT for indications other than $\mathrm{HCV}$ $(10,11)$. Functional performance may be maintained during the first two years after HCV recurrence, but subsequently deteriorates, with the magnitude of impairment related to the severity of recurrence.

Although the incidence of HCV infection is falling, the economic costs and social burden caused by HCV is expected to increase (12). This apparent discrepancy is explained by the vast numbers of asymptomatic persons who are infected with $\mathrm{HCV}$ and who are at risk for future HCV-related complications (cirrhosis, portal hypertension and hepatocellular carcinoma) unless effective, well-tolerated and affordable antiviral therapies are developed. Naturally, all economic costs must be regularly reassessed as health care policies change and as advances in the prevention and/or treatment of $\mathrm{HCV}$ infection become available. The best strategy is to focus on prevention, not transplantation.
Natural history and clinical outcome of $\mathrm{HCV}$ recurrence The natural history of HCV infection after LT is unknown. HCV reinfects the new liver in the majority of patients within the first few weeks of transplantation. The rates of both histological and clinical progression vary considerably, frustrating the transplant physician, whose task is to both manage immunosuppression and prescribe appropriate antiviral therapy $(2,13-16)$. Early short-term follow-up studies $(2,3,13,15,17)$ of HCV-positive LT recipients suggested that recurrent HCV infection led only to mild disease that did not significantly impact overall graft and patient survival (Figure 1). For example, Lumbreras et al (13) found no differences in actuarial survival rates in LT recipients with HCV infection at one, two and four years after transplantation compared with HCV-negative LT recipients. Even at five years post-LT, the rates of graft and overall patient survival were similar in $\mathrm{HCV}$-infected and uninfected recipients. More recent studies $(16,18)$, however, have demonstrated that recurrent HCV infection after LT can be a more serious disease, and that after five years, graft and patient survival is worse among HCV-positive than HCV-negative recipients.

Even more startling is the recent finding that even shorterterm survival may be reduced. A histological study (16) showed that HCV-infected patients, especially those with genotype $1 \mathrm{~b}$, exhibited a high rate of graft cirrhosis in the first four to five years after transplantation. A history of rejection episodes may also predispose to the development of cirrhosis. First-year biopsies may facilitate the early detection and management of cirrhosis $(14,16)$.

It has become clear that $\mathrm{HCV}$ recurrence after LT can lead to a wide spectrum of outcomes, ranging from minimal hepatitis to rapidly fatal fibrosing cholestatic hepatitis $(2,14,18)$. By the end of the first year after transplantation, more than $60 \%$ of patients have both biochemical and histological evidence of HCV infection $(2,15)$. Papatheodoridis et al (19) reported that $30 \%$ of LT recipients with $\mathrm{HCV}$ recurrence developed severe fibrosis or cirrhosis within a median of three years.

It has become increasingly apparent that a certain proportion of LT recipients develop an accelerated form of HCV infection with rapid histological and clinical progression. This subgroup includes many patients who have undergone transplantation in recent years, and in whom cirrhosis developed within four years of HCV recurrence $(1,14,20)$. This course is much more aggressive than that for primary $\mathrm{HCV}$ infection (without transplantation), where cirrhosis generally develops only after 20 to 30 years (4). Patients who develop significant histological HCV recurrence soon after LT are at the highest risk for progressive liver disease, which diminishes early graft and patient survival (17). The reasons for this acceleration in disease progression are not well understood. Many factors, related not only to the virus but also the donor and recipient, may play a role, but it has been suggested that immunosuppressive therapies are the most important.

\section{CHALLENGES OF RECURRENT HCV}

Assessing risk of $\mathrm{HCV}$ recurrence

Many factors influence HCV recurrence: pretransplant recipient health status, number and severity of cellular rejection episodes, donor-recipient human leukocyte antigen matching, levels of preand early post-transplant viremia, cytomegalovirus infection, 

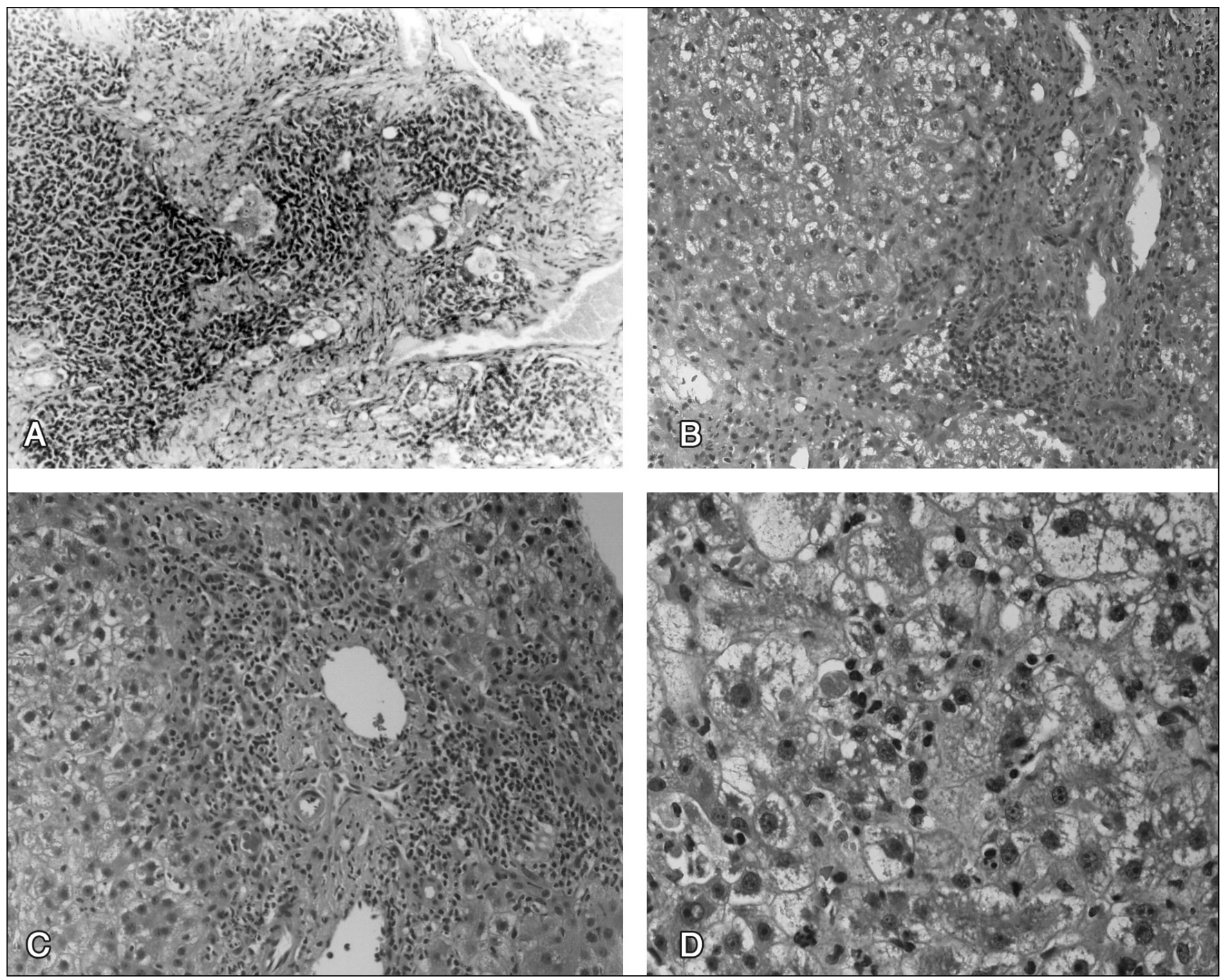

Figure 2) Histological features of liver biopsies taken from liver transplantation recipients in end-stage liver disease due to recurrent hepatitis $\mathrm{C}$ virus infection. Features include A steatosis and portal fibrosis (original magnification $\times 100$ ), B increased portal fibrosis without lymphoid aggregates (original magnification $\times 100$ ), $\mathbf{C}$ portal tract lymphoid infiltrates (original magnification $\times 100$ ), and $\mathbf{D}$ lobular inflammation and necrotic hepatocytes (original magnification $\times 400$ ). Reprinted with permission from reference 22

donor age, viral genotype and the use of a steroid bolus or other immunosuppressant medications. These factors interact to determine the long-term patient and graft outcome. Patients who experience acute cellular rejection (ACR) requiring excessive immunosuppression develop an increased HCV viral load and, potentially, more severe histological recurrence, poorer graft survival and reduced patient survival (21). Higher serum RNA levels have been correlated with more severe graft injury (20). Serum viral loads of greater than $1,250,000$ viral equivalents/mL (greater than $800,000 \mathrm{IU} / \mathrm{mL}$ ) are correlated with detection of the virus within the liver $(\mathrm{P}=0.01)(22)$ and high serum HCV RNA levels pre-LT are associated with poorer patient survival five years post-LT (1). Other studies $(2,3,23)$ have shown that only viral RNA levels measured during the first two weeks post-LT identify patients who will subsequently develop significant recurrent HCV hepatitis. Patients who receive an HCV-positive liver allograft may experience an accelerated recurrence of $\mathrm{HCV}$; therefore, this type of donor organ should be used only with caution
$(17,20)$. There is no consensus on how to identify recipients who are at high risk for severe recurrence (20).

\section{Histological nature of $\mathrm{HCV}$ recurrence}

Appropriate management for recurrent HCV depends on an accurate diagnosis. ACR may resemble HCV early after transplantation; therefore, differentiating the two is mandatory. A liver biopsy remains the 'gold standard' $(16,24)$, and an experienced hepatohistopathologist is essential.

The histological diagnosis of recurrent $\mathrm{HCV}$ is made on the basis of portal and/or periportal inflammation with mononuclear cells (Figure 2) (14,22,24-26). Findings that show a statistically significant correlation with in situ detection of hepatic viral RNA include single cell hepatocyte necrosis, bile duct damage, lymphoid aggregates and cholestasis (22). The initial appearance of fibrosis is an important predicator of progression to cirrhosis.

The histopathological features of ACR and HCV-associated recurrent hepatitis may appear at different times after 
transplantation (14). Acute HCV hepatitis typically develops between the second and fourth month after LT; in contrast, changes consistent with chronicity are usually seen more than three months after transplantation (14).

\section{Surrogate biomarkers}

There is growing interest in using surrogate biomarkers to aid in the diagnosis of recurrent HCV disease $(21,27)$. ACR and $\mathrm{HCV}$ recurrence involve different immunological mechanisms that may translate into differential expression of cell surface molecules on the liver allograft. Progressive and severe forms of HCV recurrence after LT may be associated with aberrant intrahepatic expression of cell surface molecules involved in lymphocyte activation, antigen recognition and cell adhesion. These molecules regulate the recruitment and activation of cytotoxic T lymphocytes. Further work is needed to determine if these observations can be translated into an effective diagnostic tool.

\section{Impact of immunosuppression on recurrent $\mathrm{HCV}$ disease}

Because of the observation that recurrent HCV is occurring much earlier, there is a concern that a novel immunosuppressive therapy may be responsible $(14,28)$. It is logical that immunosuppressants that enhance viral replication or attenuate viral clearance would increase the severity of recurrent $\mathrm{HCV}$. In practice, however, it is difficult to identify the specific effects of individual immunosuppressants on the course of posttransplant HCV. Complex drug regimens involving multiple drugs and drug-crossover protocols, as well as the interplay of host, viral and donor factors, contribute to the challenge. The literature is also plagued by anecdotal observations, nonrandomized clinical studies and retrospective data. At this time, no multicentre, randomized, controlled clinical trials have been undertaken specifically to measure the effects of individual immunosuppressive agents on the rate or severity of recurrent $\mathrm{HCV}$ disease.

Corticosteroids: There is general agreement that corticosteroids are associated with more severe histological injury. Corticosteroids promote HCV replication, thereby increasing viral levels $(20,29)$. By 12 months after transplantation, patients who have been treated with steroids for the longest duration have the highest levels of HCV RNA, and this is strongly correlated with the severity of fibrosis (30). Many immunosuppressive protocols now involve rapid tapering of steroids or are steroid-free, but this is usually accomplished by increasing the dosage of other immunosuppressive agents.

Anti-T cell antibodies: Anti-T cell antibodies may be used as induction therapy or to treat severe allograft rejection concomitantly with corticosteroids. The risk of rapid and severe HCV recurrence is correlated with the number of rejection episodes, the severity of ACRs and the use of the anti-T cell antibody, OKT3 (31-33). Rosen et al (32) reported that administration of OKT3 to LT recipients with pre-existing HCV and steroidresistant ACR was associated with a higher incidence and earlier presentation of recurrent HCV than with age-, sex- and initial immunosuppression-matched controls.

Basiliximab, an anti-CD25 monoclonal antibody that blocks the functional interaction between interleukin-2 (IL-2) and its receptor, and consequently limits the activation of $\mathrm{T}$ lymphocytes, has been shown to reduce the incidence of acute rejection episodes in LT patients $(34,35)$. However, basiliximab seems to have little effect on HCV recurrence. Histological evidence of recurrence is apparent in approximately $50 \%$ of $\mathrm{HCV}$-infected recipients in the first postoperative year (20). In a subgroup of HCV-positive LT patients treated with basiliximab and triple therapy (cyclosporine, steroids and azathioprine), the recurrence rate of HCV was $48.4 \%$ (15 of 31) (34). The duration of follow-up was only six months, however, and viral load was not assessed. At 12 months, there was no graft loss from recurrent HCV. In a larger controlled study (35), the HCV recurrence rates in LT recipients on dual therapy (cyclosporine and steroids) at 12 months were $58 \%$ ( 40 of 69 ) and $54.7 \%$ (35 of 64) in the placebo and basiliximab arms, respectively. HCV recurrence was identified by histopathological, biochemical and clinical evidence. Overall, it is not yet possible to make definitive conclusions about the effect of basiliximab on $\mathrm{HCV}$ recurrence.

It has been suggested that daclizumab, another IL-2 receptor antibody, is associated with early recurrence of HCV. LT recipients were given daclizumab, mycophenolate mofetil (MMF) and steroids, followed by tacrolimus and steroid tapering. HCV-positive patients given daclizumab had a significantly higher HCV viral load at 12 months than the control group $(13.2 \pm 6.8 \mathrm{mEq} / \mathrm{mL}$ versus $8.3 \pm 6.1 \mathrm{mEq} / \mathrm{mL} ; \mathrm{P}<0.05)$ (36). At 12 months, $92 \%$ had histological evidence of recurrent disease compared with $60 \%$ of the control population $(\mathrm{P}<0.05)$. Unfortunately, only historical controls were used in this study (1995 to 1998 versus 1998 to 2000). In addition, immunosuppression in the HCV control group consisted of low-dose tacrolimus or cyclosporine and steroids, and MMF was administered only to patients who experienced ACR. Thus, further studies are required to determine exactly how daclizumab affects HCV recurrence.

Calcineurin inhibitors: In the nontransplant setting, the calcineurin inhibitor cyclosporin A (CsA) does not affect viral levels in HCV-infected patients (20). In addition, the levels of post-LT HCV viremia are similar among those receiving CsA plus steroids or tacrolimus plus steroids (20).

Papatheodoridis et al (19) performed the first study in which LT recipients received monotherapy with a calcineurin inhibitor (CsA or tacrolimus) immediately after transplant surgery. Although this was not a randomized study, there was no evidence that CsA or tacrolimus altered the viral characteristics of treated patients. Platz et al (37) followed 137 patients who were transplanted for HCV-related cirrhosis; 79 patients received CsA-based immunosuppression and 58 patients received tacrolimus. Three-month and one-year survival rates were similar. In addition, year 1 to year 5 cumulative patient survival rates were similar in CsA-treated (67 of 79; 84.8\%) and tacrolimus-treated patients (50 of $58 ; 86.2 \%$ ). The retransplantation rates were similar $(5.1 \%$ and $6.9 \%$, respectively) (37). At present, there is little evidence to recommend the preferential use of either CsA or tacrolimus in post-LT recipients with $\operatorname{HCV}(20,37)$. Although one study (38) in Ireland and the United Kingdom, which evaluated 606 patients undergoing their first orthotopic LT, suggested that tacrolimus provided a better clinical outcome at one year than microemulsified CsA.

MMF: MMF has both immunosuppressive and antiviral properties and, in theory, could provide benefits to some recipients with recurrent HCV disease $(20,37,39,40)$. Like the antiviral 
agent, ribavirin, MMF is an inosine monophosphate dehydrogenase inhibitor and enhances the antiviral activity of antiherpes agents $(20,39,40)$. Controversy surrounds the role of MMF on $\mathrm{HCV}$ recurrence in $\mathrm{LT}$ recipients $(28,41)$. To date, various reports have concluded that MMF has had a beneficial, an adverse or no impact on the rate and severity of HCV recurrence $(20,36,37,41-45)$.

Langrehr et al (44) recently published preliminary results of a prospective study comparing a steroid-free induction regimen of tacrolimus plus MMF with a standard dual protocol of tacrolimus plus steroids. Patients were followed for two years after transplantation. The incidence of ACR in the tacrolimus/MMF arm was 26\% (four of 15), compared with $46 \%$ (seven of 15) in the tacrolimus-prednisone arm. Significant histological recurrence with fibrosis occurred in $13 \%$ (two of 15) of patients in the tacrolimus-MMF group and 20\% (three of 15) of patients in the tacrolimus-prednisone group. However, the sample size was too small to permit reliable conclusions to be drawn about the effects of MMF on HCV recurrence.

Two recent reports by Fasola et al $(42,46)$ concluded that high doses of MMF (resulting in a high "exposure ratio") lessened the impact of ACR on the incidence of severe HCV recurrence. They recommended that MMF be part of immunosuppression regimens to prevent HCV recurrence. They also concluded that the benefit of MMF in delaying $\mathrm{HCV}$ recurrence may be similar to that provided by ribavirin therapy (43).

Bahra et al (45) retrospectively analyzed their data from a small number of patients who had received MMF to treat ACR and concluded that MMF may prevent viral activation. A phase III randomized, controlled, multicentre study showed a decreased frequency of histological recurrence of HCV at six months and a trend towards decreased recurrence at 12 months in patients treated with MMF than those receiving azathioprine in a multidrug regimen (20).

Other investigators have not been as optimistic about the beneficial effects of MMF. Jain et al (41) reported that MMF had no significant impact on patient or graft survival, or the rates of graft rejection or HCV recurrence (based on both biochemical changes and histological findings). This group concluded that MMF either had no anti-HCV effect or that its immunosuppressive properties outweighed its antiviral activity in LT patients.

Other reports (47-49) have suggested that MMF has an adverse effect on HCV recurrence, with an increased incidence of recurrent hepatitis and jaundice, and more severe histological findings (47-49). Nelson et al (36) found that the combination of anti-IL-2 receptor antibodies (daclizumab) with MMF soon after transplantation was associated with earlier and more severe HCV recurrence: $45 \%$ of MMF-daclizumab-treated patients developed advanced disease within one year compared with $26 \%$ of controls (36).

Perhaps the current situation is best summarized by Charlton (28), who stated that “...on aggregate the reported data...provide no compelling basis for either administering or avoiding MMF in HCV-infected liver transplant". Indeed, one should be careful not to draw premature conclusions from the data. Studies have varied in terms of MMF dosage and treatment duration. Immunosuppression may be only one of many factors influencing the risk of HCV after LT. The 'best' immunosuppressive regimen for HCV-infected LT recipients remains unclear and can be identified only by prospective, randomized, controlled trials.

\section{Optimal treatment for recurrent $\mathrm{HCV}$}

The management of recurrent HCV infection after LT remains a major challenge $(41,50)$. Strategies aimed at reducing the risk of developing severe $\mathrm{HCV}$ recurrence include withdrawing steroids as early as possible. Early and accurate identification of high-risk patients would allow the prompt administration of antiviral therapy $(31,51)$. Other strategies include the manipulation of immunotherapy to reduce the risk of ACR without affecting viral kinetics (2). Antiviral treatments are available but are of limited efficacy and tolerability.

Preventing overimmunosuppression in $\mathrm{HCV}$ recurrence: Regimens with two or three immunosuppressive agents are significantly more likely than single-drug treatments to result in advanced histological disease, including severe fibrosis (19). In addition, it is possible that the choice of initial immunosuppression affects the eventual histology of HCV recurrence. A recent study by Papatheodoridis et al (19) revealed that the initial use of a single immunosuppressant was associated with an inhibition of or delay in the development of severe fibrosis without increasing the number of ACR episodes. They also demonstrated that initial triple-immunosuppressive therapy tended to be associated with higher HCV RNA levels at 12 months than was treatment with a single immunosuppressant $(\mathrm{P}=0.058)(30)$.

Recent data (52) suggest that up to $70 \%$ of LT recipients develop ACR, but that many of these episodes resolve spontaneously. This observation, together with evidence that the liver is a tolerogenic organ, mandates a re-evaluation of current immunosuppressive regimens. Goddard (52) suggested that a robust form of allograft acceptance or tolerance should be established in LT recipients, which would allow more rapid dosage reduction or withdrawal of immunosuppressive agents. This approach may allow us to overcome some of the shortcomings of conventional immunosuppression regimens.

Antiviral treatments: Antiviral agents are important to the treatment of HCV recurrence but are limited in terms of efficacy and tolerability. Various strategies have been proposed in an attempt to optimize treatment: pretransplant prophylaxis to prevent graft infection, pre-emptive therapy immediately after transplantation to prevent chronic hepatitis and treating established disease to prevent cirrhosis and graft failure (53). However, it is not easy to determine when to implement a particular strategy, and in whom.

Currently, ribavirin (a broad-spectrum antiviral nucleoside that acts as a viral mutagen), in combination with interferon alpha (IFN- $\alpha$ ), is often used as first-line therapy (25,54-59). When both ribavirin and IFN- $\alpha$ were administered to patients with recurrent HCV after LT, HCV RNA levels were reduced and histology was improved $(56,58)$. An initial virological response has been observed in 35\% to $88 \%$ of cases, but a sustained viral response (SVR) occurred much less frequently $(25,60,61)$, and the therapy was associated with significant toxicity $(1,56)$.

The addition of a polyethylene glycol (PEG) molecule to IFN- $\alpha$ creates peginterferon- $\alpha$ (PEG-INF- $\alpha$ ). This drug has a prolonged half-life and duration of action, and therefore requires only once-weekly administration. Clinical trials involving non-LT patients have demonstrated that PEG-INF- $\alpha$ 
is superior to standard IFN- $\alpha$ in clearing $\mathrm{HCV}$, with comparable safety (62-64). Ribavirin and PEG-IFN- $\alpha$ combination therapy produced SVR rates as high as $54 \%$ (65). Studies to determine the efficacy of PEG-IFN- $\alpha$ with ribavirin in LT recipients are underway, but rates of SVR greater than $20 \%$ are expected.

Improved understanding of the immunological correlates of HCV clearance would assist the development of effective immunotherapeutic agents. For example, cytotoxic T lymphocytes may control viral replication and may also be responsible for progressive liver damage (66). Various treatment strategies are being developed such as the inhibition of HCV replication using novel RNA viral mutagens. Specific antiviral targets that have been identified include the HCV NS3 serine protease, RNA helicase, RNA-dependent RNA polymerase, the internal ribosomal entry site and the putative cell surface receptor CD81. Gene therapy targets HCV gene expression and replication. $T$ cell-based vaccines are being considered against highly immunogenic and immunodominant molecules (eg, NS3 and NS4) as a means of enhancing the T cell response against HCV without damaging the liver $(67,68)$. Some of these approaches are already being evaluated in clinical trials $(59,68)$, and may complement existing therapeutic modalities in the future.

Retransplantation: Liver retransplantation may be the only viable option for patients whose allograft fails because of recurrent HCV disease. In the US, approximately $10 \%$ of transplanted HCV patients die from recurrent disease. Most experts agree that up to $20 \%$ of LT recipients with recurrent HCV cirrhosis will eventually require retransplantation. Moreover, in the US, retransplantation accounts for approximately $10 \%$ of all liver transplants $(1,69,70)$. These numbers will almost certainly increase as graft failure develops with time after transplantation (1,69). Biggins et al (69) have shown that liver retransplantation surgery is more costly than primary transplantation and has less certain outcomes. These facts create a serious ethical dilemma for the transplant community, because the large numbers of patients requiring retransplantation may prevent many others from receiving their first liver allograft.

The rapid development of primary graft failure from HCV recurrence predicts poor graft and patient survival after repeat transplantation $(69,70)$. While the preponderance of data confirm this statement, other studies $(20,71,72)$ suggest that retransplantation for $\mathrm{HCV}$ recurrences may be more successful than previously thought. Kim et al (71) conducted a multicentre prospective, randomized trial that revealed four-year survival rates for $\mathrm{HCV}$-positive retransplanted patients that were comparable with those of retransplanted patients without HCV (71). In a study based on the United Network for Organ Sharing database, Rosen et al (73) noted that HCV status did not significantly affect patient survival after retransplantation.

An early decision to perform retransplantation may offer the patient a more favorable outcome (72). Recognizing end-stage recurrent disease and undertaking timely retransplantation may improve survival rates. Retransplantation should be considered soon after portal hypertension has been detected $(31,74)$. Methods of predicting outcome are being established. Sheiner et al (31) reported that preoperative hyperbilirubinemia was the single most important indicator of poor prognosis. In addition, Rosen et al $(70,73)$ reported that retransplanted recurrent HCV recipients with preoperative cholestasis and very poor renal function had very poor outcomes after retransplantation, regardless of whether retransplantation was performed early or late.

As the proportion of the first generation of LT patients who develop severe recurrent HCV and graft failure increase, the current policies governing organ allocation will be challenged. Indeed, recurrent HCV disease will become the most serious problem facing the transplantation community (70). As a guide to making the 'best' choice of whether to retransplant, Rosen et al (73) developed a model to predict the survival of patients undergoing this procedure using five readily accessible parameters: age, bilirubin, creatinine, United Network for Organ Sharing status and cause of graft failure. Living-related LT procedures may or may not be the solution, and there have been anecdotal reports of severe fibrosing cholestatic hepatitis in this setting.

\section{CONCLUSIONS}

HCV almost always recurs in LT recipients. The natural history is not known and patients experience a range of outcomes. Within five years of transplantation, recurrent HCV disease is usually mild and survival is generally preserved. $\mathrm{HCV}$ recurrence leads to liver failure in $2 \%$ to $8 \%$ of patients shortly after LT, and in up to $20 \%$ over the long term. Without effective medical management, retransplantation may be the only lifesaving option. While there is currently no completely effective anti-HCV treatment, antiviral therapy is a valuable evolving option. Large, well-controlled, prospective clinical trials are needed to determine the optimal immunosuppressive regimen for treating recurrent $\mathrm{HCV}$ in $\mathrm{LT}$ recipients.

Although the factors that determine the severity of recurrent $\mathrm{HCV}$ infection have not yet been elucidated, new therapeutic agents under clinical evaluation may prevent allograft rejection, avoid excessive immunosuppression and, therefore, not exacerbate the effects of $\mathrm{HCV}$ recurrence.

The burden of ESLD secondary to HCV recurrence is growing. Given the critical organ shortage and increased costs associated with retransplantation surgery and recovery, transplant teams must rethink their approach. Despite attempts to improve patient outcomes post-retransplantation, the shortage of organ donors and the appearance of aggressive forms of recurrent HCV in recent years might lead to such a poor prognosis that transplant surgeons may refuse to perform retransplantation (73). Gaps in our knowledge prevent us from formulating an effective clinical approach to this problem. The situation urgently demands a better understanding of viral biology, new antiviral therapies and clarification of the impact of immunosuppression on disease recurrence. Ethical considerations must be addressed in any discussion of treatment options, survival and costs.

\section{REFERENCES}

1. Bourgeois N. Hepatitis C recurrence after liver transplantation. Acta Gastroenterol Belg 1999;62:428-31.

2. Samuel D, Feray C. Recurrence of hepatitis $C$ virus infection after liver transplantation. J Hepatol 1999;31(Suppl 1):217-21.

3. Gane EJ, Portmann BC, Naoumov NV, et al. Long-term outcome of hepatitis C infection after liver transplantation. N Engl J Med 1996;334:815-20.

4. Lauer GM, Walker BD. Hepatitis C virus infection. N Engl J Med 2001;345:41-52. 
5. Busch MP. Insights into the epidemiology, natural history and pathogenesis of hepatitis $C$ virus infection from studies of infected donors and blood product recipients. Transfus Clin Biol 2001;8:200-6.

6. Di Bisceglie AM. Hepatitis C. Lancet 1998;351:351-5.

7. Frank C, Mohamed MK, Strickland GT, et al. The role of parenteral antischistosomal therapy in the spread of hepatitis $\mathrm{C}$ virus in Egypt. Lancet 2000;355:887-91.

8. Alter MJ, Kruszon-Moran D, Nainan OV, et al. The prevalence of hepatitis C virus infection in the United States, 1988 through 1994. N Engl J Med 1999;341:556-62.

9. Leigh JP, Bowlus CL, Leistikow BN, Schenker M. Costs of hepatitis C. Arch Intern Med 2001;161:2231-7.

10. Paterson DL, Gayowski T, Wannstedt CF, et al. Quality of life in long-term survivors after liver transplantation: Impact of recurrent viral hepatitis C. Clin Transplant 2000;14:48-54.

11. Feurer ID, Wright JK, Payne JL, et al. Effects of hepatitis C virus infection and its recurrence after liver transplantation on functional performance and health-related quality of life. J Gastrointest Surg 2002;6:108-15.

12. Armstrong GL, Alter MJ, McQuillan GM, Margolis HS. The past incidence of hepatitis $\mathrm{C}$ virus infection: Implications for the future burden of chronic liver disease in the United States. Hepatology 2000;31:777-82.

13. Lumbreras C, Colina F, Loinaz C, et al. Clinical, virological, and histologic evolution of hepatitis $\mathrm{C}$ virus infection in liver transplant recipients. Clin Infect Dis 1998;26:48-55.

14. Berenguer M, Lopez-Labrador FX, Wright TL. Hepatitis C and liver transplantation. J Hepatol 2001;35:666-78.

15. Böker KH, Dalley G, Bahr MJ, et al. Long-term outcome of hepatitis $\mathrm{C}$ virus infection after liver transplantation. Hepatology 1997;25:203-10.

16. Prieto M, Berenguer M, Rayon JM, et al. High incidence of allograft cirrhosis in hepatitis $\mathrm{C}$ virus genotype $1 \mathrm{~b}$ infection following transplantation: Relationship with rejection episodes. Hepatology 1999;29:250-6.

17. Ghobrial RM, Steadman R, Gornbein J, et al. A 10-year experience of liver transplantation for hepatitis C: Analysis of factors determining outcome in over 500 patients. Ann Surg 2001;234:384-94.

18. Sánchez-Fueyo A, Restrepo JC, Quinto L, et al. Impact of the recurrence of hepatitis $\mathrm{C}$ virus infection after liver transplantation on the long-term viability of the graft. Transplantation 2002;73:56-63.

19. Papatheodoridis GV, Davies S, Dhillon AP, et al. The role of different immunosuppression in the long-term histological outcome of $\mathrm{HCV}$ reinfection after liver transplantation for $\mathrm{HCV}$ cirrhosis. Transplantation 2001;72:412-8.

20. Charlton M. Hepatitis C infection in liver transplantation. Am J Transplant 2001;1:197-203.

21. Sreekumar R, Rasmussen DL, Wiesner RH, Charlton MR. Differential allograft gene expression in acute cellular rejection and recurrence of hepatitis $\mathrm{C}$ after liver transplantation. Liver Transpl 2002;8:814-21.

22. Nuovo GJ, Holly A, Wakely P Jr, Frankel W. Correlation of histology, viral load, and in situ viral detection in hepatic biopsies from patients with liver transplants secondary to hepatitis C infection. Hum Pathol 2002;33:277-84.

23. Gretch DR, Bacchi CE, Corey L, et al. Persistent hepatitis C virus infection after liver transplantation: Clinical and virological features. Hepatology 1995;22:1-9.

24. Brunt EM. Grading and staging the histopathological lesions of chronic hepatitis: The Knodell histology activity index and beyond. Hepatology 2000;31:241-6.

25. Knodell RG, Ishak KG, Black WC, et al. Formulation and application of a numerical scoring system for assessing histological activity in asymptomatic chronic active hepatitis. Hepatology 1981;1:431-5.

26. Narayanan Menon KV, Poterucha JJ, El-Amin OM, et al. Treatment of posttransplantation recurrence of hepatitis $\mathrm{C}$ with interferon and ribavirin: Lessons on tolerability and efficacy. Liver Transpl 2002;8:623-9.

27. Asanza CG, Garcia-Monzon C, Clemente G, et al. Immunohistochemical evidence of immunopathogenetic mechanisms in chronic hepatitis $\mathrm{C}$ recurrence after liver transplantation. Hepatology 1997;26:755-63.

28. Charlton MR. Mycophenolate and hepatitis C: Salve on a wound or gasoline on a fire? Liver Transpl 2002;8:47-9.
29. Gane EJ, Naoumov NV, Qian KP, et al. A longitudinal analysis of hepatitis $\mathrm{C}$ virus replication following liver transplantation. Gastroenterology 1996;110:167-77.

30. Papatheodoridis GV, Barton SG, Andrew D, et al. Longitudinal variation in hepatitis $C$ virus (HCV) viraemia and early course of HCV infection after liver transplantation for HCV cirrhosis: The role of different immunosuppressive regimens. Gut 1999;45:427-34.

31. Sheiner PA, Schwartz ME, Mor E, et al. Severe or multiple rejections are associated with early recurrence of hepatitis $\mathrm{C}$ after orthotopic liver transplantation. Hepatology 1995;21:30-4.

32. Rosen HR, Shackleton CR, Higa L, et al. Use of OKT3 is associated with early and severe recurrence of hepatitis $\mathrm{C}$ after liver transplantation. Am J Gastroenterol 1997;92:1453-7.

33. Hirose R. Pros and cons of using interleukin-2 receptor antibodies in liver transplant recipients. Liver Transpl 2002;8:143-5.

34. Calmus Y, Scheele JR, Gonzalez-Pinto I, et al. Immunoprophylaxis with basiliximab, a chimeric anti-interleukin-2 receptor monoclonal antibody, in combination with azathioprine-containing triple therapy in liver transplant recipients. Liver Transpl 2002;8:123-31.

35. Neuhaus P, Clavien PA, Kittur D, et al, for the CHIC 304 International Liver Study Group. Improved treatment response with basiliximab immunoprophylaxis after liver transplantation: Results from a double-blind randomized placebo-controlled trial. Liver Transpl 2002;8:132-42.

36. Nelson DR, Soldevila-Pico C, Reed A, et al. Anti-interleukin-2 receptor therapy in combination with mycophenolate mofetil is associated with more severe hepatitis $\mathrm{C}$ recurrence after liver transplantation. Liver Transpl 2001;7:1064-70.

37. Platz KP, Mueller AR, Berg T, et al. Searching for the optimal management of hepatitis $\mathrm{C}$ patients after liver transplantation. Transpl Int 1998;11(Suppl 1):S209-S11.

38. O'Grady JG, Burroughs A, Hardy P, Elbourne D, Truesdale A, for the UK and Republic of Ireland Liver Transplant Study Group. Tacrolimus versus microemulsified ciclosporin in liver transplantation: The TMC randomized controlled trial. Lancet 2002;360:1119-25.

39. Wiesner R, Rabkin J, Klintmalm G, et al. A randomized doubleblind comparative study of mycophenolate mofetil and azathioprine in combination with cyclosporine and corticosteroids in primary liver transplant recipients. Liver Transpl 2001;7:442-50.

40. Neyts J, Andrei G, De Clercq E. The novel immunosuppressive agent mycophenolate mofetil markedly potentiates the antiherpesvirus activities of acyclovir, ganciclovir and penciclovir in vitro and in vivo. Antimicrob Agents Chemother 1998;42:216-22.

41. Jain A, Kashyap R, Demetris AJ, Eghstesad B, Pokharna R, Fung JJ. A prospective randomized trial of mycophenolate mofetil in liver transplant recipients with hepatitis C. Liver Transpl 2002;8:40-6.

42. Fasola CG, Netto GJ, Christensen LL, et al. Delay of hepatitis C recurrence in liver transplant recipients: Impact of mycophenolate mofetil on transplant recipients with severe acute rejection or with renal dysfunction. Transplant Proc 2002;34:1561-2.

43. Fasola CG, Netto GJ, Jennings LW, et al. Recurrence of hepatitis C in liver transplant recipients treated with mycophenolate mofetil. Transplant Proc 2002;34:1563-4.

44. Langrehr JM, Neumann UP, Lang M, et al. First results from a prospective randomized trial comparing steroid-free induction therapy with tacrolimus and MMF versus tacrolimus and steroids in patients after liver transplantation for HCV. Transplant Proc 2002;34:1565-6.

45. Bahra M, Neumann UP, Harren M, et al. Significance of mycophenolate mofetil treatment in patients with HCV reinfection after liver transplantation: Impact on clinical course and histologic damage. Transplant Proc 2002;34:2934-5.

46. Fasola CG, Klintmalm GB. Hepatitis C and mycophenolate mofetil a clarification. Liver Transpl 2002;8:411-2.

47. Berenguer M, Crippin J, Gish R, et al. A model to predict severe HCV-related disease following liver transplantation. Hepatology 2003;38:34-41.

48. Zekry A, Gleeson M, Guney S, McCaughan GW. A prospective cross-over study comparing the effect of mycophenolate versus azathioprine on allograft function and viral load in liver transplant recipients with recurrent chronic HCV infection. Liver Transpl 2004;10:52-7. 
49. Rostaing L, Izopet J, Sandres K, Cisterne JM, Puel J, Durand D. Changes in hepatitis $\mathrm{C}$ virus RNA viremia concentrations in longterm renal transplant patients after introduction of mycophenolate mofetil. Transplantation 2000;69:991-4.

50. McHutchison JG. Ribavirin and interferon for recurrent posttransplantation HCV infection: To treat or not to treat? Hepatology 1997;26:505-6.

51. Sreekumar R, Gonzalez-Koch A, Maor-Kendler Y, et al. Early identification of recipients with progressive histologic recurrence of hepatitis C after liver transplantation. Hepatology 2000;32:1125-30.

52. Goddard S, Adams DH. New approaches to immunosuppression in liver transplantation. J Gastroenterol Hepatol 2002;17:116-26.

53. Chan SE, Rosen HR. Outcome and management of hepatitis $\mathrm{C}$ in liver transplant recipients. Clin Infect Dis 2003;37:807-12.

54. Poynard T, Marcellin P, Lee SS, et al. Randomised trial of interferon alpha2b plus ribavirin for 48 weeks or for 24 weeks versus interferon alpha2b plus placebo for 48 weeks for treatment of chronic infection with hepatitis $\mathrm{C}$ virus. International Hepatitis Interventional Therapy Group (IHIT). Lancet 1998;352:1426-32.

55. Cameron CE, Castro C. The mechanism of action of ribavirin: Lethal mutagenesis of RNA virus genomes mediated by the viral RNA-dependent RNA polymerase. Curr Opin Infect Dis 2001;14:757-64

56. Bizollon T, Palazzo U, Ducerf C, et al. Pilot study of the combination of interferon alfa and ribavirin as therapy of recurrent hepatitis C after liver transplantation. Hepatology 1997;26:500-4.

57. Lavezzo B, Rizzetto M. Treatment of recurrent hepatitis C virus infection after liver transplantation. J Hepatol 1999;31(Suppl 1):222-6.

58. Teuber G, Berg T, Hoffmann RM, et al. Retreatment with interferon-alpha and ribavirin in primary interferon-alpha non-responders with chronic hepatitis C. Digestion 2000;61:90-7.

59. Crotty S, Cameron C, Andino R. Ribavirin's antiviral mechanism of action: Lethal mutagenesis? J Mol Med 2002;80:86-95.

60. Kornberg A, Hommann M, Tannapfel A, et al. Long-term combination of interferon alfa- $2 \mathrm{~b}$ and ribavirin for hepatitis $\mathrm{C}$ recurrence in liver transplant patients. Am J Transplant 2001;1:350-5.

61. De Vera ME, Smallwood GA, Rosado K, et al. Interferon-alpha and ribavirin for the treatment of recurrent hepatitis $\mathrm{C}$ after liver transplantation. Transplantation 2001;71:678-86.

62. Lindsay KL, Trepo C, Heintges T, et al. A randomized, doubleblind trial comparing pegylated interferon alfa- $2 \mathrm{~b}$ to interferon alfa-2b as initial treatment for chronic hepatitis C. Hepatology 2001;34:395-403.

63. Zeuzem S, Feinman SV, Rasenack J, et al. Peginterferon alfa-2a in patients with chronic hepatitis C. N Engl J Med 2000;343:1666-72.

64. Reddy KR, Wright TL, Pockros PJ, et al. Efficacy and safety of pegylated $(40-\mathrm{kd})$ interferon alpha-2a compared with interferon alpha-2a in noncirrhotic patients with chronic hepatitis C. Hepatology 2001;33:433-8.

65. Manns MP, McHutchison JG, Gordon SC, et al. Peginterferon alfa-2b plus ribavirin compared with interferon alfa- $2 \mathrm{~b}$ plus ribavirin for initial treatment of chronic hepatitis C: A randomised trial. Lancet 2001;358:958-65.

66. Freeman AJ, Marinos G, French RA, Lloyd AR. Immunopathogenesis of hepatitis $\mathrm{C}$ virus infection. Immunol Cell Biol 2001;79:515-36.

67. Lamonaca V, Missale G, Urbani S, et al. Conserved hepatitis C virus sequences are highly immunogenic for CD4+ T cells: Implications for vaccine development. Hepatology 1999;30:1088-98.

68. Moradpour D, Blum HE. Current and evolving therapies for hepatitis C. Eur J Gastroenterol Hepatol 1999;11:1199-202.

69. Biggins SW, Beldecos A, Rabkin JM, Rosen HR. Retransplantation for hepatic allograft failure: Prognostic modeling and ethical considerations. Liver Transpl 2002;8:313-22.

70. Rosen HR. Retransplantation for hepatitis C: Implications of different policies. Liver Transpl 2000;6(Suppl 2):S41-6.

71. Kim WR, Charlton MR, Wiesner R, et al. Patient and graft survival following hepatic retransplantation in patients with hepatitis $\mathrm{C}$. Hepatology 2000;32:257A. (Abst)

72. Ghobrial RM. Retransplantation for recurrent hepatitis C. Liver Transpl 2002;8(Suppl 1):S38-S43.

73. Rosen HR, Madden JP, Martin P. A model to predict survival following liver retransplantation. Hepatology 1999;29:365-70.

74. Ghobrial RM, Farmer DG, Baquerizo A, et al. Orthotopic liver transplantation for hepatitis C: Outcome, effect of immunosuppression, and causes of retransplantation during an 8-year single-center experience. Ann Surg 1999;229:824-31. 


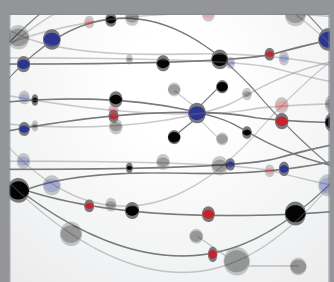

The Scientific World Journal
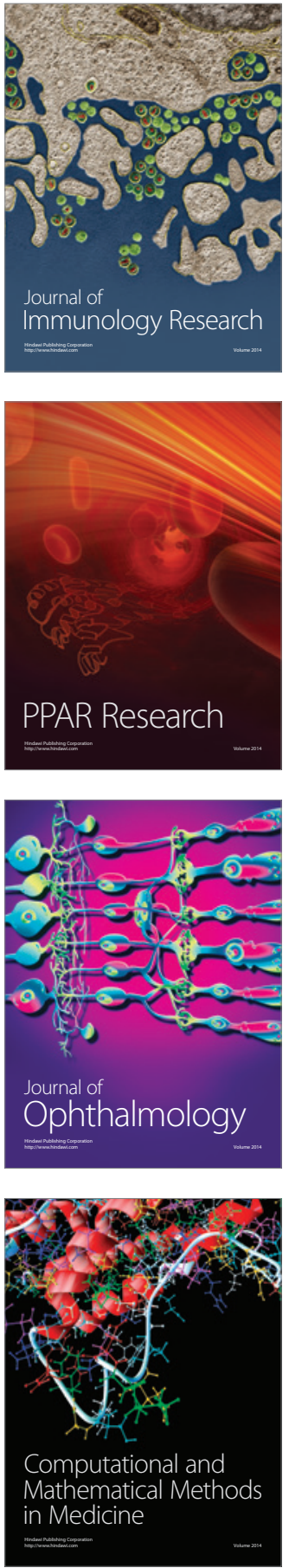

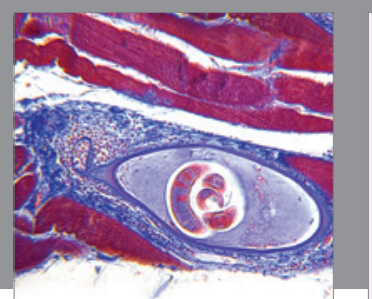

Gastroenterology Research and Practice

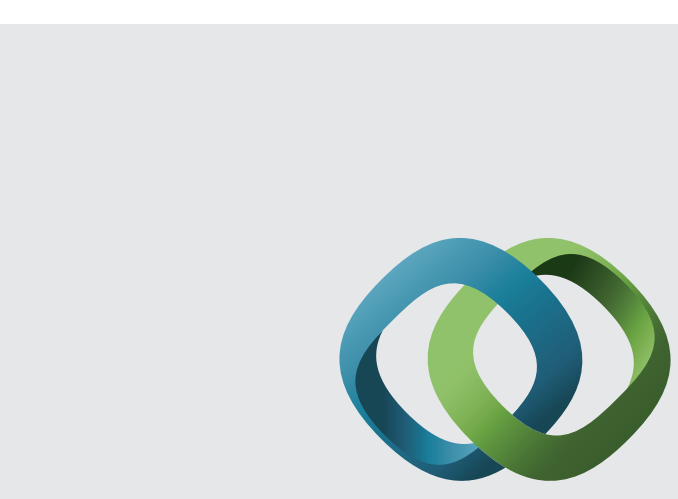

\section{Hindawi}

Submit your manuscripts at

http://www.hindawi.com
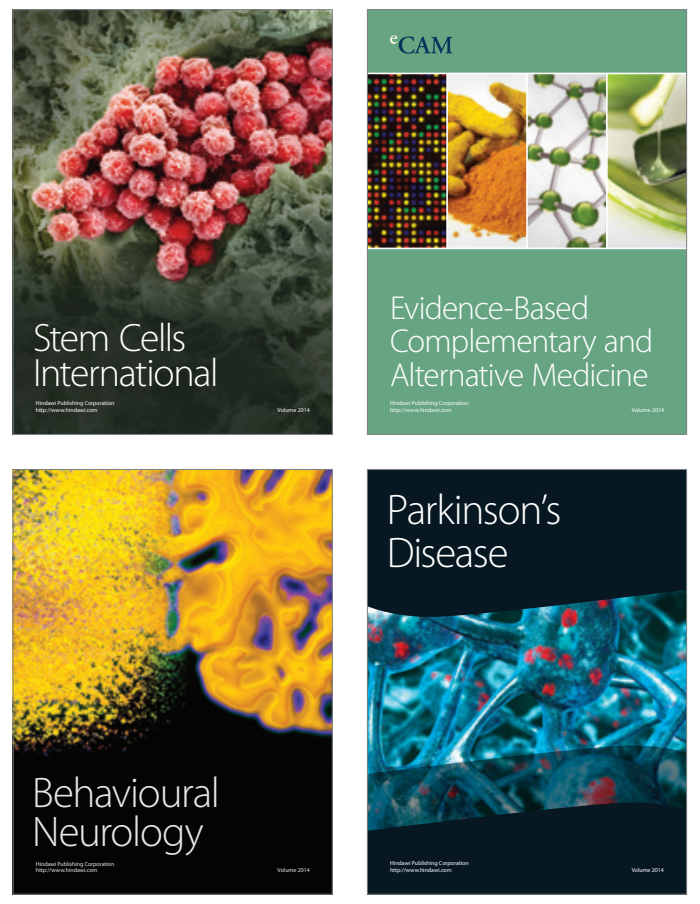
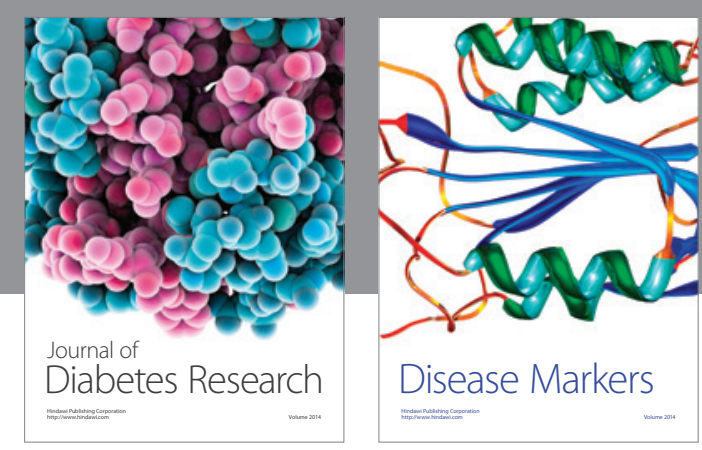

Disease Markers
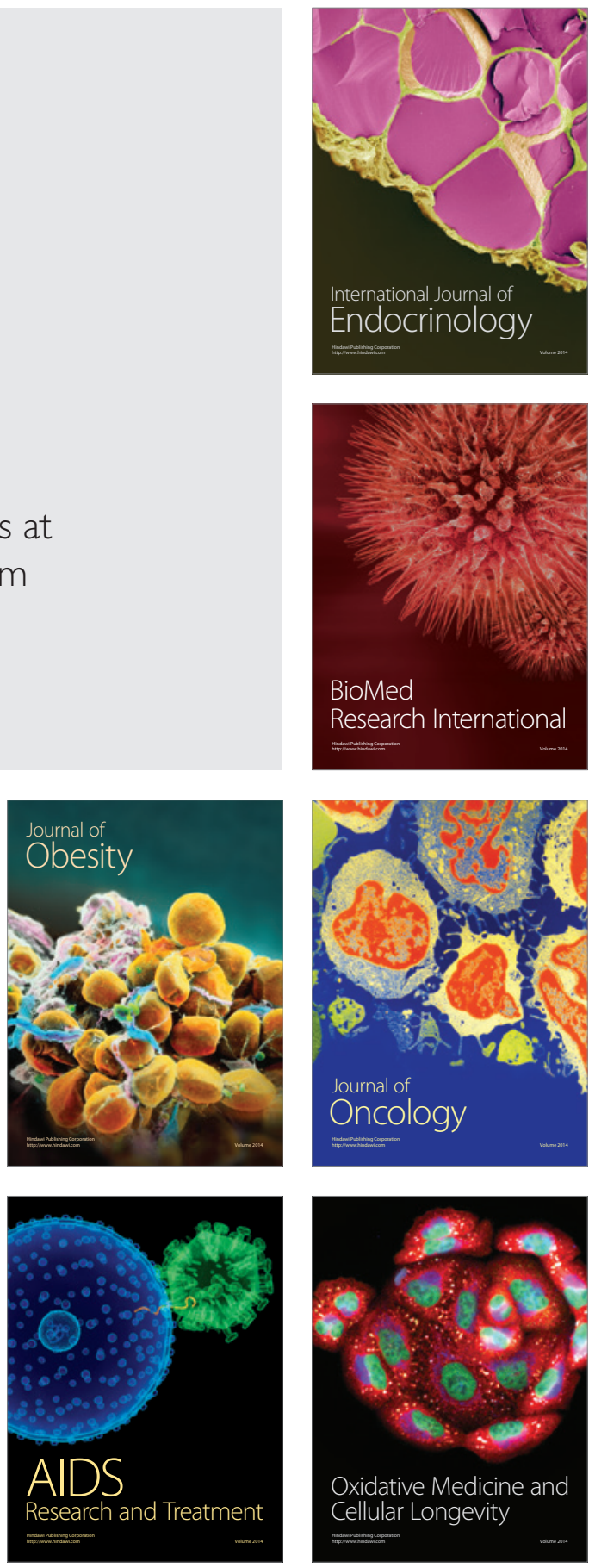